\title{
DIAGNÓSTICO DE HEMOPARASITOSE ATRAVÉS DA TÉCNICA DE DISTENSÃO DE GOTA DE COÁGULO SANGUÍNEO'
}

\author{
DIAGNOSIS OF HEMOPARASITOSIS TROUGH THE SPREAD-SMEAR \\ TECHNIQUE USING A DROP OF BLOOD CLOT
}

Neusa Saltiél STOBBE; Eunice Leonora CHAPLIN”; Maria das Graças de Souza PAIVA; Nilton Rogério Santos SILVA”; Fívio A. Pacheco ARAÚUJo'; Elinor FORTES

\begin{abstract}
RESUMO
O desempenho da técnica de distensão de Gota de Coágulo de sangue, entre as coloraçð̄es de Giemsa diluído c puro, ć avaliado cm relaçăo à possibilidade de observação dos clementos figurados c da presença de Babesia bovis, Babesia bigemina e Anap lasma marginale. Utilizou-sc um bovino, com 6 meses de idade inoculado com os agentes da Tristeza Parasitária, como doador das amostras de sangue. A técnica permitiu a obscrvaçåo dos critrócitos, lcucócitos e dos hemoparasitas.
\end{abstract}

UNITERMOS: Babesia; Anaplasma marginale; Diagnóstico; Técnicas; Bovinos

\section{INTRODUÇĀO}

As distensōes finas vêm sendo utilizadas nos cxames de sangue, em análises clínicas e em diagnósticos de hemoparasitoses, desde o início do século até os dias de hoje s.11, 14, 25. Após a colheita do sanguc, pode ocorrer hemólise pela agitaçảo da amostra, altas temperaturas c substâncias que diminuem a tensão superficial ${ }^{4}$ sendo que a distensão deve ser confeccionada em uma a duas horas após a colheita, para que se mantenham as condiçð̋es idcais de exame ". Em amostras velhas de sanguc, os critrócitos podem apresentar artefatos de técnica e muitos lcucócitos podem mostrar-se degenerados $^{8,11}$. A ocorrência de anisocitose leve a moderada é considerada fisiológica $\mathrm{cm}$ bovinos ${ }^{11,13}$.

Uma das docnças de bovinos, responsávcis por clevadas perdas econômias, é a Tristeza Parasitária ${ }^{16,20}$ sendo que os primeiros sinais clínicos de babcsiose ocorrem entre o $8^{\circ} \mathrm{e} 16^{\circ}$ dias após a inoculação dos agentes pelo Vetor ${ }^{17}$. Os corpúsculos iniciais de Anaplasma marginale podem aparecer na circulação a partir do $5^{\circ}$ dia da inoculação, porém os marginais tem aprescntação máxima próxima ao $20^{\circ}$ dia perdurando por duas semanas ${ }^{21}$.

O diagnóstico pode ser realizado por testes sorológicos, porém, poucos laboratórios nos países tropicais estão preparados para sua utilizaçăo ${ }^{1720}$. Para o diagnóstico pós-morte podese utilizar esfregaços de órgåos para pesquisa dos agentes que mantêm suas características morfológicas inalteradas por alguns dias $1,2,7,9,10,12,15,26$.

Baseando-se nos resultados obtidos $\mathrm{cm}$ esfregaços de órgãos e devido ao limite de tempo de confecção das distensð̄es finas de sanguc CHAPLIN el al. ${ }^{3}$ (1987) desenvolveram a técnica de esfregaço de fragmento de coágulo de sanguc. A partir dessa técnica STOBBE et al. ." (1988) desenvolveram uma técnica alternativa, que utiliza uma gota de sangue obtida ao cortc do coágulo.
Pcsquisa scmelhante foi rcalizada por FUJI SAKI ct al. ${ }^{6}$ (1989) que resgatou Theileria sergenti atravês de filtração do coágulo sanguínco por pressão.

A coagulação do sangue ocorre em período de 30 a 60 minutos ${ }^{22}$, complctando-sc com a transformação do fibrinogênio $\mathrm{cm}$ fibrina c com a scparaçāo do soro ${ }^{13,19}$. O fibrinogênio, que pode cstar $\mathrm{cm}$ maior quantidade $\mathrm{cm}$ processos inflamatórios agudos ${ }^{11}$, tem afinidade pela membrana critrocítica ${ }^{27}$. Durante a formaçāo do coágulo, leucócitos c critrócitos parasitados, devido ao scu maior tamanho c menor peso específico, permanccem na parte mais alta, consistindo a porção lardácca do coágulo ${ }^{8}, 11,13,26$, com exeção de alguns lcucócitos que migram para o soro devido aos scus movimentos amebóides 4 .

$\mathrm{Na}$ coloração de hemoparasitas, normalmente $\mathfrak{e}$ utilizado o método de Giemsa ${ }^{10,14,18}$ sendo que algumas alteraçб̄es de coloração podem scr atribuídas à variação do $\mathrm{pH}$ da supcrfícic da lấmina, a crros no proccssamento da técnica como também à degencração de lcucócitos.

O presentc trabalho mostra alguns resultados obtidos com a técnica de gota de coágulo de sanguc, com o objetivo de apresentar uma altcrnativa de técnica para cxame de sangue, principalmente de hemoparasitas.

\section{MATERIAL E MÉTODO}

O expcrimento teve lugar nos laboratório c estábulo do Sctor de Protozoologia da Faculdade de Veterinária da Universidade Federal do Rio Grande do Sul, Porto Alegre.

Foram estabclecidos 2 grupos com a técnica de distensão de gota de coágulo de sanguc, um com coloração pelo método de Gicmsa diluído ${ }^{14,18}$ c outro pelo método de Giemsa puro.

Um bovino esplenectomizado, de origem curopéia, com aproximadamente 6 meses de idade, negativo para Babesia bovis

\footnotetext{
1-Trabalho apresentado como um dos requisitos para o grau de mestre $\mathrm{cm}$ Mcdicina Vetcrinária pela Universidade Federal do Rio Grande do Sul, financiado pela UFRS.

2-Mestranda em Medicina Veterinária da Universidade Federal do Rio Grande do Sul; bolsista do CNPq: Caixa Postal 2172, Porto Alegre-RS, Brasil.

3-Professor - Faculdade de Medicina Vetcrinária da Univ. Foderal do Rio Grande do Sul.

4.Professor - Instituto de Biociências da Universidade Federal do Rio Grande do Sul.
} 
pelo teste de imunofluorescência indircta, c ncgativo para todos os agentes $\mathrm{cm}$ distensð̋es de lâmina, foi inoculado com sangue de outro bovino, comprovadamente portador dos agentes da Tristcza Parasitária c cntæo usado como doador das amostras de sangue.

As amostras de sangue foram colhidas, scm anticoagulante, nos dias 8,10,12,22, 24, 26 após a inoculação, mantidas $\mathrm{cm}$ temperatura ambiente c em repouso por uma hora, para ocorrer a coagulação, após o que, foram réfrigcradas até scu processamento. Foram confeccionadas 4 lâminas de cada amostra de coágulo, num total de 24 , pela técnica de distensão de gota obtida a partir do coágulo de sangue descrita a scguir:

- retirar o coágulo do soro;

- secar a supcrfícic externa do coágulo cm papel absorventc;

- cortar o coágulo transversalmente próximo da zona lardácea;

- raspar icvemente a superfícic seccionada com a borda de uma lâmina capturando assim uma gota;

- distender a gota conforme a técnica de distensão fina de sanguc;

- secar imediatamentc.

Das 4 lâminas de cada amostra, 2 foram coradas pclo mélodo de Gicmsa diluido e 2 pelo mélodo de Giemsa puro. Todas as amostras foram processadas no mesmo dia da colhcita, com excoção da amostra do dia 26 que foi processada 24 horas após.

A observação da aprescntação dos critróxitos c lcucócitos foi fcita de acordo com STOBBE ${ }^{23}$ (1990) c a detcrminação das parasitemias por Babesia bovis, Babesia begemina c Anaplasma marginale conforme recomendaçāo do INSTITUTO INTERAMERICANO DE COOPERAÇÃO PARA A AGRICULTURA ${ }^{10}$ (1985), com objetiva de imersāo num total de 1000 vezes de aumento.

\section{RESULTADOS}

A observação da qualidade de confeç̧⿸丆o de lâminas (Tab. 1, 2 c 3) apresentou os seguintes resultados:

- a visualização foi boa $\mathrm{cm}$ todas as lâminas com presença de poucos depósitos de corante cm 2/3 das lâminas (Tab. 1);

- cerca de $2 / 3$ das lâminas apresentaram menos de 50\% dos erituócitos dcformados (Tab. 2);

- a anisocitose foi leve a moderada durante o período experimental (Tab. 2);

- a coloração dos critrócitos foi predominantemente vermetho tijolo com o corantc puro c rosa com o diluído (Tab. 2);

- a maioria das lâminas aprescntou boa distribuição dos eritrócitos somente nas extremidades e número médio de eritrócitos por campo maior que 500 (Tab. 2);

- o grupo do corante diluído revelou maior quantidade de lcucócitos, corando-os melhor do que os do puro (Tab. 3).

A observação do número de Babesia bovis, Babesia bigemina c de Anaplasma marginale nas lâminas de esfregaço de coágulo apresentou os seguintes resultados:

- o número de Babesia bovis foi maior no $8^{\circ}$ dia nas lâminas de csfregaço do grupo GIEMSA DILUÍDO, porém seu maior númcro foi detectado no $24^{\circ}$ dia no grupo GIEMSA PURO;
- o maior númcro rcgistrado de Babesia bigemina foi nas lâminas de ambos os grupos no $12^{\circ}$ dia, sendo que o agentc næo foi visualizado nos $8^{\circ}, 10^{\circ}, 24^{\circ}$ e $26^{\circ}$ dias.

- o maior númcro detcctado de Anaplasma marginale foi nas lâminas de esfregaço do grupo GIEMSA DILUíDo no $26^{\circ}$ dia, cstando presente nos $22^{\circ}$ e $24^{\circ}$ dias. As lâminas de csfregaço do coágulo do grupo GIEMSA PURO aprescntaram o agentc apenas no $24^{\circ}$ dia.

\section{DISCUSSĀO}

A boa visualização apresentada por todas as lâminas indica que a técnica de distensăo de gota de coágulo manteve condiç̋̃es satisfatórias para o exame de sanguc. As porcentagens de deformação encontradas nos critrócilos (Tab. 2) c lcucócitos (Tab. 3) podem estar relacionadas com o tempo decorrido entre a colhcita $\mathrm{c}$ a confeç̧⿸丆̃o das lâminas ", sendo que é comum encontrar-sc muitos leucócitos degencrados $\mathrm{cm}$ distensöes finas de sanguc ${ }^{8}$.

A ausĉncia do soro na gota utilizada ${ }^{13} \mathrm{c}$ a aglutinação dos critrócitos determinada pelo fibrinogênio, principalmentc nos processos inflamatórios agudos ${ }^{11,26}$ dificultariam a scparação destas células, detcrminando um númcro médio por campo bastante clevado na maioria das lâminas, com uma boa distribuição principalmente nas bordas da distensão (Tab. 2).

O tempo de atuaçăo do corante provavelmente detcrminou a coloração mais intensa dos critrócitos (Tab. 2) c dos leucócitos (Tab. 3), scndo que a melhor coloraçăo do esfregaço pode ter permitido a detecção da maior quantidade de agentes no grupo diluído.

Nenhum destes fatores, no entanto, parece ter interferido na obscrvação da anisocitose, nos grupos de coloração, que sc manteve dentro da normalidade para bovinos ${ }^{11,13}$.

As difcrenças encontradas entre os 2 grupos na quantificação dc Babesia bovis c o scu maior registro ocorrido no $24^{\circ}$ dia c não entre o $8^{\circ}$ c $16^{\circ}$ dias citado por MAHONEY ${ }^{17}$ (1977), podem ser atribuídos ao local do coágulo utilizado c à possível retenção de critrócitos parasitados na rede de ribrina ${ }^{8.11}$, apesar de que estes critrócitos podem ser extraídos com alguma pressāo ". Esses fatores também podem cstar relacionados com a quantificação obtida de Babesia bigemina.

As diferenças encontradas na quantificaçăo de Anaplasma marginale parecem estar rclacionadas com os locais do coágulo destinados a cada grupo $c$ ao tempo de atuação do corantc, onde o grupo diluído apresentou clevados percentuais da riquétsia, quando comparado com o grupo puro.

\section{CONCLUSŌES}

- a técnica de distensão de gota de coágulo permitiu a obscrvação dos clementos figurados no exame de esfregaço de sanguc;

- a técnica pode ser utilizada no diagnóstico laboratorial de Babesia spp c Anaplasma marginale.

- a coloraçăo com Gicmsa diluído apresentou melhor desempenho que o puro na visualização dos clementos figurados c na quantificaçāo de Anaplasma marginale. 
STOBBE, N. S.; CHAPLIN, E. L.; PAIVA, M. G. S.; SILVA, N. R. S.; ARAÚJO, F. A. P.; FORTE:S, E. Diagnóstico de hemoparasitose através da técnica de distensāo de gola de có́gulo sanguíneo. Braz. J. ve. Res. anim., Säo Paulo, v.29, p. 390-393, 1992. Suplemento.

TABELA 1

Observação dos esfregaços obtidos a parir do coágulo segundo a visualização geral e presença de resíduos de corante e sua distribuição nos grupos (em número de lâmina). Pono Alcgre.

\begin{tabular}{lcc}
\hline Aspectos observados & GIEMSA PURO & GIEMSA DILUIDO \\
\hline a. Visualização geral & & \\
- impossível & 0 & 0 \\
- difícil & 0 & 0 \\
- razóável & 0 & 0 \\
b. Residuos de corante & & \\
- raro & 1 & 1 \\
- pouco & 8 & 8 \\
- bastante & 2 & 3 \\
- muito & 1 & 0 \\
\hline
\end{tabular}

TABELA 2

Observação dos critrócitos quanto à aprescntação e distribuição nos esfregaços de coágulo (cm número de lâminas). Porto Alegre.

\begin{tabular}{|c|c|c|}
\hline Aspectos observados & GIEMSA PURO & GIEMSA DILUIDO \\
\hline \multicolumn{3}{|l|}{ a. Conformação dos critrócitos } \\
\hline - menos de $25 \%$ deformados & 3 & 5 \\
\hline$-26-50 \%$ deformados & 4 & 3 \\
\hline$-51-75 \%$ deformados & 5 & 4 \\
\hline - mais de 76\% deformados & 0 & 0 \\
\hline \multicolumn{3}{|l|}{ b. Anisocitose } \\
\hline - leve & 6 & 6 \\
\hline - moderada & 6 & 6 \\
\hline - acentuada & 0 & 0 \\
\hline \multicolumn{3}{|l|}{ c. Coloraçāo } \\
\hline - vermelho tijolo & 10 & 2 \\
\hline - rosa claro & 2 & 6 \\
\hline - rosa cscuro & $\mathbf{0}$ & 4 \\
\hline - azulada & 0 & 0 \\
\hline \multicolumn{3}{|l|}{ 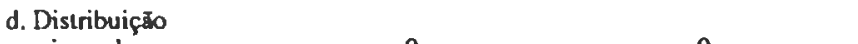 } \\
\hline - irregular & 0 & 0 \\
\hline - muito juntos & 2 & 0 \\
\hline - boa nas cxtremidades & 6 & 8 \\
\hline - boa cm loda lâmina & 4 & 4 \\
\hline \multicolumn{3}{|l|}{ e. Número médio/campo } \\
\hline$-200 / 350$ & 1 & 2 \\
\hline$-351 / 500$ & 3 & 2 \\
\hline$-501 / 650$ & 4 & 3 \\
\hline - mais de 650 & 4 & 5 \\
\hline
\end{tabular}

TABELA 3

Observação dos leucócitos quanto à apresentaçāo e distribuiçāo nos csfregaços de coágulo (em número de lâminas). Porno Alegre.

\begin{tabular}{|c|c|c|}
\hline Aspectos observados & GIEMSA PURO & GIEMSA DILUIDO \\
\hline $\begin{array}{l}\text { a. Quantidade de lcucócitos } \\
\text { - raros } \\
\text { - poucos } \\
\text { - bastantc } \\
\text { - muitos }\end{array}$ & $\begin{array}{l}+ \\
2 \\
4 \\
2 \\
0\end{array}$ & $\begin{array}{l}2 \\
4 \\
7 \\
1\end{array}$ \\
\hline $\begin{array}{l}\text { b. Conformação } \\
\text { - menos de } 25 \% \text { deformados } \\
\text { - } 26-50 \% \text { deformados } \\
\text { - } 51-75 \% \text { deformados } \\
\text { - mais de } 76 \% \text { deformados }\end{array}$ & $\begin{array}{l}+ \\
4 \\
2 \\
0 \\
2\end{array}$ & $\begin{array}{l}2 \\
6 \\
1 \\
3\end{array}$ \\
\hline $\begin{array}{l}\text { c. Coloraçāo } \\
\text { - não corados } \\
\text { - fracamente corados } \\
\text { - só núcleo corado } \\
\text { - bern corados }\end{array}$ & $\begin{array}{l}4 \\
6 \\
0 \\
2\end{array}$ & $\begin{array}{l}0 \\
0 \\
3 \\
9\end{array}$ \\
\hline
\end{tabular}

+ Foi impossivel analisar a conformação e quantidade de lcucócitos $\mathrm{cm}$ quatro lâminas de esfregaço de cóagulo do grupo GIEMSA PURO.

\section{AGRADECIMENTOS}

Ao Instituto de Pesquisas Veterinárias Desidério Finamor c ao técnico Agnelo Ribciro somos gratos por todos os auxílios prestados.

\section{SUMMARY}

The spread-smear lochnique using a drop of blood clot and stainod by diluted and undimitod Giemsa stain was evaluated for the search of blood cell types and recognition of Babesia bovis, Babesia bigemina and Anaplasma marginak hemoparasitcs. The blood clo samples were taken from a 6 month-old calf experimentally inoculated with the blood from a Caulc Tick Fever carrier. The Technique was sumitable for the observation of different blood cells and for the rocognition of the hemoparasites.

\section{REFERÊNCIAS BIBLIOGRÁFICAS}

01-CALLOW, L. L.; JOHNSTON, L. A. Y. Babesia spp. in the brains of clinically normal cattle and their detection by a brain smear technique. Aust. vet. J., v. 39, p. 25-31, 1963.

02-CALLOW, L. L.; McGAVIN, M. D. Cercbral babesiosis due to Babesia argentina. $\Lambda$ ust. vet. J., v. 39, p. 15-21, 1963.

03-CHAPLIN, E. L.; STOBBE, N. S.; ARAÚJO, F. A. P.; SILVA, N. R.S. Diagnóstico laboratorial de hemocitozoários através de esfregaço de sangue coagulado (Nota Prévia). Arq. Fac. Vet. Univ. Fed. R. G. Sul, v. 15/16, p. 65, 1987/88.

04-DUKES, H.H. Fisiologla de los animales domesticos. 3.cd. Madrid, Aguilar, 1969. p. 17-62.

05-FONSECA, A.; BRAGA, A. Noçōes sobre a tristeza parasitária dos bovinos. Rio de Janciro, Ministério da Agricultura, 1924.

06-FUII SAKI, K.; KAMIO, T.; NAKAMURA, Y.; SHIMURA, K.; TAKAMASHI, Y.; KAWAZU, S.; SHIMIZU, S.; MINAMI, $T$.; ITO, $S$. Theileria sergenti: a simple mcthod for isolation of isolation of piroplasma from crythrocytes. Jap. J. vet. Sci., v. 51, p. 457-9. 1989.

07-HADANI, A.; HAAN, L.; GONZALEZ DE RIOS, L.; GUGLIELMONE, A. A.; BERMUDEZ, A.; MANGOLD, A. The detection of babesiosis in bovines by the indirect immunofluorescent antibody test compared to the prevalence of $B$. bovis in cercbral smcars. Brit. vet. J., v. 139, p. 1208-12,1983.

08-HAM, A. W. Histologia. 7.ed. Rio de Janciro, Guanabara Koogan, 1977. p. 756.

09.HOYTE, H.M.D. Differential diagnosis of Babesia argentina and Babesia bigemina infections in cattle using thin blood smears and brain smears. Aut vet. J., v.47, p. 248-50, 1971.

10-INSTUTUTO INTERAMERICANO DECOOPERACION PARA LA AGRICULTURA. Técnicas para el diagnostico de babesiosisy anaplasmosis bovina. San Josk, p. 79, f. 12, 1985.

11-JAIN, N.C. Schalm's veterinary hematology. 4. cd. Philadelphia, Lea \& Febiger, 1986. p.1221.

12-KESSLER, R. H.; MADRUGA, C. R.; SCHENK, M. A. M.; RIBEIRO, O. C. Babcsiosc cercbral por Babesia bovis (Babćs 1888, Starcovic 1893) cm bezerros no Estado de Mato Grosso do Sul. Pesq. Agropec. bras., v.18, p. 931-5, 1983.

13-KOLB, E. Fisiologia veterinária. 2.cd. Zaragoza, Acriba, 1976. p. $420-82$.

14-LANGERON, M. Précis de microscople. 6.ed. Paris, Masson et ctc., 1942. p. 736-64. 
STOBBE, N. S.; CHAPLIN, E. L.; PAIVA, M. G. S.; SILVA, N. R. S.; ARAUJO, F. A. P.; FORTES, E. Diagnóstico de hemoparasitose através da técnica de distensto de gola de cófgulo sanguíreo. Braz. J. vet. Res. anlm., Sảo Paulo, v.29, p. 390-393, 1992. Suplemento.

15-LEEFLANG, P. Diagnosis of Babesia argentina infections in cattle using brain smears. Aust. vet. J., v.48, p.72, 1972.

16-McCOSKER, P. J. The global importance of babesiosis. In.: RI STIC, M.; KREIER, J. P. Babeslosis. New York, Academic Press, 1981.p. 1-24.

17-MAHONEY, D. F. Babeda in domestic animals. In: KREIER, J.P. Parasitic protozoa. New York, Academic Press, 1977.v.4, p. 1-52.

18-PINTO, C. Zooparasitos de interesse médlco e veterinário. Rio de Janeiro, Pimenta de Mello, 1938. p. 316.

19-REGOECZI, E.; BRAIN, M. C. Organ distribution of fibrin in disseminated intravascular coagulation. Brit.J. Haemat., v.17, p. 73-81, 1969.

20-RI STIC, M.; LEVY, M. G. A new era of research toward solution of bovine babesiosis. In.: RI STIC, M.; KREIER, J. P. Babeslosk. New York, Academic Press, 1981. p. 509-43.

21-RI STIC, M.; WATRACH, A.M. Anaplasmosis. V. Studies and hypothesis conceming the cycle of development of the causative agent. Amer. J. vet. Res., v.24, p. 267-77, 1963.

22-SCHOTTELIUS, B. A.; SCHOTTELIUS, D. D. Textbook of physiology. 7.ed. Saint Louis, Mosby co., 1973. p. 214-40.
23-STOBBE,N.S. Cóngulo de sangue nodiagnóstico de hematozoários, desenvol vimento e comparação entre técnicas. Porto Alcgrc, 1990. Dissertação (Mestrado) - Faculdade de Vetcrinária, Universidade Federal Rural do Rio Grande do Sul.

24-STOBBE, N.S.; CHAPLIN, E.L.; PAIVA, M.G.S.; ARAÚJO, F.A.P.i SILVA, N.R.S. Diagnóstico laboratorial de hemocitozoários através da distensão de gota de coágulo de sangue (Nota Prévia). In: CONGRESSO ESTADUAL DE MEDICINA VETERINÁRIA, 10., Porto Alcgrc, 1988. Anais. Porto Alcgre, SOVERGS, 1988. p. 61.

25-VARELA, M. E. Leciones de hematologia. 5.cu. Bucnos Aircs, El Alenco, 1942.p. 382.

26-VILENBERG, G. Diagnosis of Babesia argentina infoction in caulc using brain smears. Aust. vet. J., v.48, p. 534, 1972.

27-WRIGHT, I. G. Biochemical characteristics of Babesia and physicochemical reactions in the host. In. : RI STIC, M.; KREIER, J. P. Babesiosis. New York, Acadcmic Press, 1981. p. 171-205.

Recebido para publicação cm 19/08/91 Aprovado para publicação $\mathrm{cm} 08 / 07 / 92$ 